\title{
VOLUMETRIC ASSESSMENT OF TUMOR SIZE CHANGES IN PEDIATRIC LOW GRADE GLIOMAS: FEASIBILITY AND COMPARISON WITH LINEAR MEASUREMENTS
}

Felice D'Arco ${ }^{1,2^{*}}$ Patricia O'Hare ${ }^{3 *}$, Fatima Dashti ${ }^{1}$, Alvaro Lassaletta ${ }^{4}$, Thalia Loka ${ }^{3}$, Uri Tabori ${ }^{4}$, Giacomo Talenti ${ }^{2}$, Stefanie Thust. ${ }^{5}$, Giancarlo Messalli ${ }^{6}$, Patrick Hales ${ }^{7}$, Eric Bouffet $^{4}$, Suzanne Laughlin ${ }^{1}$

\section{Authors Affiliations:}

${ }^{1}$ Pediatric Neuroradiology, Department of Diagnostic Imaging, The Hospital for Sick Children, Toronto, Canada.

${ }^{2}$ Pediatric Neuroradiology, Department of Radiology, Great Ormond Street Hospital, London, UK

${ }^{3}$ Department of Pediatric Oncology, Great Ormond Street Hospital, London, UK.

${ }^{4}$ Division of Pediatric Neuro-oncology, The Hospital for Sick Children, Toronto, Canada

${ }^{5}$ National Hospital for Neurology and Neurosurgery, Queen Square, London, UK.

${ }^{6}$ Radiology Unit, "Villa Malta" Hospital, Sarno, Italy

${ }^{7}$ Developmental Imaging and Biophysics Section, Institute of Child Health, University College London, London, UK

*FD'A and PO'H are joint first authors and contributed equally to this study.

\section{Corresponding author}

Felice D'Arco

Department of Pediatric Neuroradiology

Great Ormond Street Hospital NHS Trust, WC1N, 3JH

London, United Kingdom

Phone: 0044 (0)20 74059200

Email: Felice.D’Arco@gosh.nhs.uk 


\begin{abstract}
Purpose: We report a retrospective comparison between bi-dimensional RANO criteria and manual volumetric segmentation (MVS) in pediatric low grade gliomas.

Methods: MRI FLAIR or T1 post contrast images were used for assessment of tumor response. 70 patients were included in this single center study, for each patient two scans were assessed ("time 0" and "end of therapy") and response to therapy was evaluated for both methods. Inter-reader variability and average time for volumetric assessment were also calculated.
\end{abstract}

Results: 14 (20\%) of the 70 patients had discordant results in terms of response assessment between the bi-dimensional measurements and MVS. All volumetric response assessments were in keeping with the subjective analysis of tumor (radiology report). Of the 14 patients, 6 had stable disease (SD) on MVS and progressive disease (PD) on 2D assessment, 5 patients had SD on MVS and partial response (PR) on 2D assessment, 2 patients had PD on MVS and SD on 2D assessment, and 1 patient had PR on MVS and SD on 2D analysis. The number of discordant results rises to 21(30\%) if minor response is integrated in the response assessment. MVS was relatively fast and showed high interreader concordance.

Conclusion: Our analysis shows that therapeutic response classification may change in a significant number of children by performing a volumetric tumor assessment. Furthermore MVS is not particularly time consuming and has very good inter-reader concordance.

\title{
Keywords:
}

Volumetric; RANO; Pediatric Low Grade Gliomas; MRI; tumor response.

\section{INTRODUCTION}

Pediatric low grade gliomas (pLGGs) are a heterogeneous category of neoplasms, consisting most commonly of pilocytic astrocytomas with a favorable 5-year survival rate, but potential for 
recurrence, particularly in those incompletely resected [1,2]. Although some pLGGs in accessible locations, such as the cerebellum, may be surgically cured, a large number of children will require adjuvant treatment.

Over the last decades, chemotherapy has been increasingly used in the management of unresectable and/or progressive pLGGs, particularly in young children [3]. It has therefore become essential to titrate adjuvant therapies carefully to tumor response. Together with the patient's clinical condition, imaging assessment forms the principal criterion by which pLGGs treatment efficacy is measured, whereby one of the major challenges is response quantification. Currently there is no widely validated method for pediatric brain tumor response assessment [4].

The Macdonald criteria were first published in 1990 as guidelines for response assessments in adult supratentorial malignant gliomas, using the product of perpendicular measurements of enhancing tumor on axial post contrast images as a measure of tumor burden [5]. To incorporate non-enhancing tumor changes into the response assessment, and to address the problem of 'pseudoprogression', the RANO criteria were subsequently published in 2010 [6]. Despite some gain in assessment accuracy compared to previous methods, there are major limitations to the RANO criteria [7] and there is neither evidence nor consensus for the usefulness of these criteria in pLGGs.

First of all enhancement of pLGGs is variable, heterogeneous and not representative of the tumor grade [8]. Additionally, there is no clear consensus that an objective response translates to improvements in progression-free survival [4], with some authors reporting good correlation between response and progression-free survival [9], and others not [10]. Pediatric brain tumors as a whole, and pLGGs in particular, differ significantly in prognosis and clinical course compared to their adult counterparts. The extrapolation of parameters of assessment for adult malignant gliomas has not been validated in the pediatric setting and it is probably suboptimal [11]. 
pLGGs are non-spherical and often have complex, mixed solid and cystic components. Some irregularly shaped neoplasms such as visual pathway and hypothalamic gliomas may not be amenable to surgery but have a significant risk of progression. In view of this, accurate imaging assessment in this group of patients is particularly important and this is why RANO assessment criteria for pLGGs have included minor response criteria to include tumors which show a $25-49 \%$ reduction in the area of non-enhancing lesion on T2/FLAIR [12].

Several studies have evaluated the role of one dimensional, two dimensional and volumetric assessment of size in brain tumors [13] [14]. These studies have largely focused on adult cohorts of patients, and include two pediatric comparative studies: the first by Warren et al, of One-, Twoand Three-dimensional measurements of childhood high grade brain tumors [15], and the second by Kilday et al on a small cohort ( $\mathrm{n}=8$ ) of pLGGs [16].

The aim of this study was to perform a comparison between bi-dimensional measurements of tumor diameter based on the RANO method and manual volumetric segmentations (MVS) for pLGGs to determine response assessment. Furthermore we evaluated the clinical feasibility of manual volumetry in terms of time consuming and inter-reader concordance.

\section{METHODS}

\section{Study population}

Patients with LGG treated with weekly vinblastine at Sickkids (SK) hospital were included in this study. Some of the patients were from a phase II Canadian trial [17], the rest were treated as SK policies. Patients were included in the study if there was consensus between the two neuroradiologists (SL and FD'A, with respectively 25 and 3 years of experiences as pediatric neuroradiologist) that there was evidence of clearly measurable disease. Six patients with neurofibromatosis type 1 (NF1) were excluded since clear distinction between tumor and NF1related foci of abnormal signal intensity (FASI) was difficult at the level of the basal ganglia. 
All patients underwent MR imaging assessment at several time points (weeks 26, 39, 52, and 70). For each patient, 2 scans were analyzed: time point 'zero' is defined as the baseline scan (within 4 weeks prior to the initiation of vinblastine), and follow up examination at the end of therapy (average 522 days). Each subject was assigned to one of the categories "progressive disease (PD)", "stable disease (SD)" or "tumor partial response (PR)" using data available in literature for each the 2D and volumetric assessment. Patients were considered eligible for analysis if their tumor measured at least $10 \times 10 \mathrm{~mm}$ in maximum perpendicular diameter (definition of measurable lesion according to RANO criteria) and if the tumor could be visualized on a minimum of 4 consecutive slices. Tumors within the spinal cord, and patients with evidence of metastatic disease were excluded from the analysis.

\section{Image acquisition}

The MR images used for tumor assessment were FLAIR images, with the exception of those patients, in whom complete enhancement was present on the T1 post contrast sequences on both the scans. All images were acquired on either 1.5 Tesla or 3 Tesla Achieva scanners (Philips, The Netherlands) using a body coil for transmission and an 8-channel head coil for signal reception. The standard brain protocol consisted of: coronal T2WI (weighted images) (repetition time [TR]/echo time [TE]: 4811/ 120 ms; slice/gap: 5/1 mm; field of view [FOV]: 220 x 194 x 119 mm; acquisition matrix: 400 x 289), axial FLAIR (TR/TE: 7000/ 140 ms; slice/gap: 5/1 mm; FOV: $220 \times 181 \times 119 \mathrm{~mm}$; acquisition matrix: $292 \times 222$ ), axial diffusion weighted images (DWI) (TR/TE: 4799/ 70 ms; slice/gap: 5/0 mm; FOV: 150 x 198 x 150 mm; acquisition matrix: $100 \times 132$ ), pre and post gadolinium axial 3D T1 turbo field echo with reformats in sagittal and coronal planes (TR/TE: 9.9/ $4.6 \mathrm{~ms}$; voxel size 1 x 1 x $0.5 \mathrm{~mm}$; FOV: 220 x 220 x $162 \mathrm{~mm}$; acquisition matrix: 220 x 220). 


\section{DATA ANALYSIS.}

The margins of tumor and ideal sequences to identify the tumor margins, were established by consensus between the two neuroradiologists. The majority of tumors showed variable enhancement, and delineation of tumor borders was best achieved in T2 FLAIR in $72 \%$ of patients. However for completely enhancing tumors, for example chiasmatic optic pathway gliomas, the T1 post contrast sequences achieved higher resolution than flair and so calculations were based on these sequences. For 2D analysis of tumor burden a measurement in millimeters was taken of the maximal tumor diameter on a single axial FLAIR (or axial T1 post contrast section if applicable). The product of the 2 diameters was calculated to form the tumor bidimensional measurement $[14,18]$, with the same sequence for each patient being used for MVS. The decision if to use the $\mathrm{T} 1$ post contrast sequences was based on the opinion of the radiologist, depending on whether the enhancing component was judged to represent the entire tumor burden.

MVS was undertaken by two pediatric neuroradiologists for all lesions (FD'A, FD). The tumor outline was delineated on axial images manually for each MR image showing the lesion. The volume was then calculated using the 'region of interest (ROI) volume calculate' plugin of the Osirix DICOM viewer (Osirix MD v.7.0.3, FDA cleared K101342, Pixmeo SARL, Switzerland), with intergap correction for FLAIR images [15] (Figure 1). Table 1 shows response criteria for both 2D and volumetric assessments as described in literature [18]. Minor response is quoted as a $25-49 \%$ decrease in the product of the perpendicular diameters on 2D measurements. For volumetric response criteria, progressive disease was defined as $\geq 40 \%$ increasing in calculated volume $[18,19]$. This assumption of spherical volume presumes equal growth of tumor in each direction. Because RANO has extrapolated dimensions on the basis of a spherical shape of tumor, we further extrapolated this formula to include volumetric dimensions to facilitate comparison between the two methods. Other geometric models for tumor volume include the ellipsoid, cylinder and rectangular formulas. The ellipsoid model defines volume as $1 / 6 \pi \mathrm{LWH}$, where L,W,H represent diameters in the three axes of the tumor (length, width and height) [20], 
while the rectangular formula defines the product of LWH. The formula for the Cylinder model is $\mathrm{V}=\pi(\mathrm{W} / 2)^{2} \mathrm{~L}$. Schmidt et al assess that the ellipsoid geometric model most closely approximates tumor volume, however both spherical and ellipsoid calculations showed significant variance in this comparison and correlations were poor, $\mathrm{R}=0.62$ and 0.531 for ellipsoid and spherical models respectively [21]. A volumetric minor response criteria can be extrapolated from orthogonal diameter measurement using the formula from $\mathrm{V}=4 / 3 \pi \mathrm{r} 3$ to include tumors with a $35-64 \%$ decrease in volume. We have therefore further sub-categorized patients to include minor response. It is important to note that the cut-off values for volumetric assessment represent a mathematical extrapolation from the linear values; in fact there are no prospective clinical studies available suggesting specific values for therapy response using volumetrics in pediatric brain tumors [18]. All baseline and follow up MRI studies were reviewed by a certified pediatric neuro-radiologist (SL) to determine, if the volumetric assessment was consistent with the subjective interpretation of the changes in tumor size. The inter-reader variability in volumetric assessment was calculated on a sample of 12 baseline scans from the same study cohort using intraclass correlation coefficient (ICC).

\section{RESULTS:}

\section{Patient Characteristics:}

A total of 70 patients, aged 0.56 to 16.75 years with a diagnosis of pLGGs were included in the study. 37 patients were male. 55 patients had a histologically proven diagnosis of pLGGs. 15 patients did not undergo biopsy, however 14 of these had radiological appearances of an optic pathway glioma (OPG), of whom 9 had a history of NF1. 1 further patient with NF1 and a 
hypothalamic tumor did not undergo biopsy. 13 of the 70 patients had a pre-existing diagnosis of NF1. Patient demographics are listed in table 2.

\section{Response assessments:}

The results in terms of difference in tumor size (\%) between time zero and end-of-therapy followup are summarized in table 3. The median interval between studies is 522 days. On average, it took 10-15 minutes to complete MVS per patient / per scan. This did not include the time taken to export data and only included ROI drawing and software calculation of volume. ROI drawing time ranged between 5.5-10 minutes and 7.3 to 14.9 minutes for Reader 1 (FD'A), and reader 2 (FD) respectively. Time taken to reach consensus on superior sequences for defining margins of the tumor is not included.

14 (20\%) of the 70 patients showed discordant results between 2D and MVS. Of these, 6 patients had SD on MVS with 2D assessment categorizing the response as PD. 5 patients had SD on MVS with partial response (PR) identified on 2D assessment. 2 patients had PD on MVS, but SD was observed on 2D assessment. 1 patient had PR on MVS, but SD reported on 2D assessment. Of the 6 patients who had SD on volumetric analysis, but PD on 2D assessment, 2 were pLGGs NOS, and 2 were pilocytic OPGs. The other 2 patients had tumors located in the thalamus and posterior fossa. Of the 5 patients with SD on MVS and PR on 2D, 4 patients had a diagnosis of OPG. 8 of the 14 discordant patients had OPG, i.e. $22 \%$ of all OPG patients studied.

In 56 of 70 patients, the volumetric and 2D tumor assessments were deemed to be concordant in terms of the response assessment. Of these 56, 5 were concordant but with more than $50 \%$ difference in the measurement of disease response observed between the two methods. All of these 5 patients had PD, and for these patients the volumetric measurements showed a greater degree of progression compared to the bi-dimensional measurement. Of the remaining 51 patients with concordant measurements by both methods, 39 had SD, 7 patients had PD and 5 patients had PR. 
When minor response (MR) is integrated to the analysis, 3 of the discordant patients with SD on MVS and PR in 2D assessment become MR in volumetric assessment. 1 discordant patient with PR on MVS and SD on 2D assessment became MR in 2D. Furthermore, when integrating MR into the analysis of the previously 56 concordant patients, 6 patients change from SD to MR in both MVS and 2D assessment. A further 4 patients remain in SD on MVS but move to MR in 2D assessment. 3 patients move to MR on MVS but remain in SD on 2D assessment. Integrating MR brings the total discordant patient total to 21 (30\%) of patient cohort.

There was a very good inter-reader variability for MSV on a sample of 12 patients (ICC $=0.9$, supplementary table).

\section{DISCUSSION}

Accurate response assessment is critical to determine the impact of therapies. This is the largest study in children with pLGGs performing a direct comparison of bi-dimensional and volumetric tumor measurements. In our cohort, $20 \%$ of patients had discordant response assessments between the 2 methods. For these patients the therapeutic response classification may change by performing a volumetric tumor assessment (allowing for the mathematical extrapolation of the cut-off values). This becomes significant when considering that radiological response is used as a primary endpoint in many pLGGs trials. Glioma measurements can be challenging due to lack of a distinct tumor border, irregular lesion shape, variation in acquisition technique and head placement in the scanner [22, 23]. For pLGGs, the assessment of tumor burden according to the RANO criteria can be complicated by lack of gadolinium enhancement. Even in those pLGGs, in which contrast uptake is present, the enhancement pattern is often patchy and variable over time. In the majority of our patients, poorly 
enhancing neoplasms were present, which is significantly different from the adult glioblastomas (GBM) patient group in whom the bi-dimensional measurement criteria were devised [6].

The Macdonald criteria defined "size" as the largest cross-sectional area of the enhancing tumor [5], which is not a description suitable for most pLGGs. RANO criteria further built on this definition by including the evaluation of T2/FLAIR WI, in addition to clinical symptoms and the use of corticosteroids, but they are again based on different neoplasms and age group [6]. On imaging, pLGGs often do not exhibit surrounding edema and are best visualized on FLAIR and T2WI MRI sequences [12]. In view of the variability in contrast uptake and possible underestimation of the tumor size, $72 \%$ of children in this study underwent assessment of tumor burden using FLAIR images. Furthermore pLGGs differ considerably from adult counterpart in terms of molecular landscape and malignant transformation rate, which rarely occurs in the pediatric population [24, 25].

For both RANO and Macdonald analyses, the radiologist decides the slice that should correspond to the largest appearing cross-section image of the tumor, this approach can be problematic for lesions that are non-spherical because structural heterogeneity and irregular borders can make it difficult to decide on the representative slice. In addition slight variations on serial imaging (e.g. with a slightly different image plane, head placement etc.) might impact reproducibility of measurements in irregular lesions [4, 23] [26]. In GBM good correlation between volumetric and bi-dimensional measurements was found [13], this may be due, at least in part, to the fact that GBM grow very rapidly [27] and, therefore, small measuring errors would still produce the same result in terms of response criteria.

The subjective visual analysis of the tumor response was consistent with the volumetric measurements in all cases, including in those cases, in which the radiological reports were discordant with 2D measurements. This was probably due to the irregular shape of the tumors, which may have limited the 2D assessment accuracy based on one slice only (Figure 2). While one may argue that the volumetric assessment is only as good as judgement of a trained radiologist, clinical trials require the objectively reproducible data for analysis, and therefore a consistent method of assessment of tumor size is necessary.

The manual segmentation method used in our study is not significantly time consuming therefore 
encouraging its integration into the clinical workflow. Additionally this method has shown excellent inter-rater reproducibility in a test sample of 12 patients.

Most automatic and semi-automatic algorithms to date, have only reliably been shown to work in gadolinium enhancing lesions such as GBM [14]. In a study by Akkus et al. (2015) of semiautomated segmentation of pLGGs on MRI T1 post-contrast and T2 WI, the intra-operator variability was lower than intra-expert variability and inter-operator variability much smaller than inter-expert variability [28]. While this is encouraging for establishing a standardized method of semi-automated analysis tumor volume in future, such methods need specific software, time for the operator to check the segmentation results and may be more useful for very complex and extensive lesions such as plexiform neurofibromas than relatively small pLGG [29]. In a further study by Porz et al, semiautomated analysis of tumor volume was shown to be comparable to a full automated method of assessment [30], however, in this study all tumors were high grade enhancing masses. The lack or heterogeneity of enhancement typical of pLGGs and their relatively limited extension would likely hamper such an automated volumetric assessment and favor manual volumetric methods.

In our cohort, $20 \%$ of patients had discordant response assessments between the 2 methods. For these patients the therapeutic response classification may change by performing a volumetric tumor assessment (allowing for the mathematical extrapolation of the cut-off values). This becomes significant when considering that radiological response is used as a primary endpoint in many pLGGs trials. In the context of OPGs this may be of particular interest in view of the need to detect early tumor progression for patients whose functional vision is at risk. We would suggest volumetric assessment in pLGGs may be also valuable in clinical practice where a discrepancy exists between 2D assessment and the subjective analysis by the expert radiologist. The relatively short time taken for the volumetric assessment using our method makes this strategy useful for clinical practice. 


\section{Study Limitations:}

There are number of limiting factors of this study. One possible drawback is the need of specific software and correspondent expertise required to undertake volumetric assessment. This has been noted as a limiting factor in previous studies [14], even though our method is relatively simple to use in comparison with semi-automatic volumetric assessment.

Another aspect to be considered is the fact that for some patients we used FLAIR images while for others we used post contrast 3D T1 images. Although this makes the method not entirely consistent, when evaluating subjectively a mass, a radiologist in clinical practice critically uses the sequence where the lesion is better visualized, so it seems reasonable, in our opinion, to assess the volume using the same process. The lack of clinical data is noted to be a limiting factor of the study. The focus of this study however is to compare the methods of 2D and MVS assessment of tumor burden. The cohort of patients is part of a larger cohort of pLGG patients, whose assessment of response has not used volumetric data prospectively.

A further limiting factor is the slice thickness/gap (particularly relevant in FLAIR images); however the same limitations would influence the linear measurements and the software corrects for slice thickness/gap, with reduction of possible inaccuracies. Our method seems to be a good compromise between time and accuracy of measurement in the context of non-enhancing tumors since, at the moment, the use of automatic segmentation is not reliable [31]. Finally, as explained in the "data analysis" section, to use cut-off for volumetrics response based on a spherical mathematical extrapolation of linear measurements is suboptimal; however there are no prospective studies establishing cut-off values for LGG and this limiting factor stressed the advantage of using volumetric direct measurements.

\section{CONCLUSION}


Assessment according to RANO criteria is not reliable for complex shaped lesions such as pLGG; manual volumetric segmentation using Osirix software appears to be a feasible and more accurate method to quantify changes in tumor bulk on serial imaging. Furthermore in a significant proportion of our patients with pLGGs, volumetric segmentation results may differ substantially from bi-dimensional measurements, and may have a clinical impact in management of the patients and in evaluation of tumor response in clinical trials.

Acknowledgments: We thank Mrs Sara Falcone, Senior MR Radiographer, The Hospital for Sick Children, Toronto, Canada.

\section{Compliance with ethical standards}

Funding: No funding was received for this study

Conflict of Interest: ST receives funding support from the National Institute for Health Research, University College London Hospitals Biomedical Research Centre.

Ethical approval: All procedures performed in the studies involving human participants were in accordance with the ethical standards of the institutional and/or national research committee and with the 1964 Helsinki Declaration and its later amendments or comparable ethical standards.

Informed consent: Informed consent was obtained from all individual participants included in the study. 


\section{References}

1. Colin C, Padovani L, Chappé C, et al. (2013) Outcome analysis of childhood pilocytic astrocytomas: a retrospective study of 148 cases at a single institution. Neuropathol Appl Neurobiol 39:693-705. doi: 10.1111/nan.12013

2. Gnekow AK, Falkenstein F, von Hornstein S, et al. (2012) Long-term follow-up of the multicenter, multidisciplinary treatment study HIT-LGG-1996 for low-grade glioma in children and adolescents of the German Speaking Society of Pediatric Oncology and Hematology. Neuro Oncol 14:1265-1284. doi: 10.1093/neuonc/nos202

3. Ater JL, Zhou T, Holmes E, et al. (2012) Randomized study of two chemotherapy regimens for treatment of low-grade glioma in young children: a report from the Children's Oncology Group. J Clin Oncol 30:2641-2647. doi: 10.1200/JCO.2011.36.6054

4. Warren KE, Poussaint TY, Vezina G, et al. (2013) Challenges with defining response to antitumor agents in pediatric neuro-oncology: a report from the response assessment in pediatric neuro-oncology (RAPNO) working group. Pediatr Blood Cancer 60:13971401. doi: $10.1002 / p b c .24562$

5. Macdonald DR, Cascino TL, Schold SC, Cairncross JG (1990) Response criteria for phase II studies of supratentorial malignant glioma. J Clin Oncol 8:1277-1280.

6. Wen PY, Macdonald DR, Reardon DA, et al. (2010) Updated response assessment criteria for high-grade gliomas: response assessment in neuro-oncology working group. J Clin Oncol 28:1963-1972. doi: 10.1200/JCO.2009.26.3541

7. Pope WB, Hessel C (2011) Response assessment in neuro-oncology criteria: implementation challenges in multicenter neuro-oncology trials. AJNR Am J Neuroradiol 32:794-797. doi: 10.3174/ajnr.A2582

8. Sievert AJ, Fisher MJ (2009) Pediatric low-grade gliomas. J Child Neurol 24:1397-1408. doi: $10.1177 / 0883073809342005$

9. Laithier V, Grill J, Le Deley M-C, et al. (2003) Progression-free survival in children with optic pathway tumors: dependence on age and the quality of the response to chemotherapy--results of the first French prospective study for the French Society of Pediatric Oncology. J Clin Oncol 21:4572-4578. doi: 10.1200/JCO.2003.03.043

10. Packer RJ, Ater J, Allen J, et al. (1997) Carboplatin and vincristine chemotherapy for children with newly diagnosed progressive low-grade gliomas. J Neurosurg 86:747-754. doi: 10.3171/jns.1997.86.5.0747

11. Jaspan T, Morgan PS, Warmuth-Metz M, et al. (2016) Response Assessment in Pediatric Neuro-Oncology: Implementation and Expansion of the RANO Criteria in a Randomized Phase II Trial of Pediatric Patients with Newly Diagnosed High-Grade Gliomas. AJNR Am J Neuroradiol 37:1581-1587. doi: 10.3174/ajnr.A4782

12. van den Bent MJ, Wefel JS, Schiff D, et al. (2011) Response assessment in neurooncology (a report of the RANO group): assessment of outcome in trials of diffuse low- 
grade gliomas. Lancet Oncol 12:583-593. doi: 10.1016/S1470-2045(11)70057-2

13. Shah GD, Kesari S, Xu R, et al. (2006) Comparison of linear and volumetric criteria in assessing tumor response in adult high-grade gliomas. Neuro Oncol 8:38-46. doi: $10.1215 / \mathrm{S} 1522851705000529$

14. Kanaly CW, Mehta AI, Ding D, et al. (2014) A novel, reproducible, and objective method for volumetric magnetic resonance imaging assessment of enhancing glioblastoma. $\mathrm{J}$ Neurosurg 121:536-542. doi: 10.3171/2014.4.JNS121952

15. Warren KE, Patronas N, Aikin AA, et al. (2001) Comparison of one-, two-, and threedimensional measurements of childhood brain tumors. J Natl Cancer Inst 93:1401-1405.

16. Kilday J-P, Branson H, Rockel C, et al. (2015) Tumor volumetric measurements in surgically inaccessible pediatric low-grade glioma. J Pediatr Hematol Oncol 37:e31-6. doi: 10.1097/MPH.0000000000000168

17. Lassaletta A, Scheinemann K, Zelcer SM, et al. (2016) Phase II Weekly Vinblastine for Chemotherapy-Naïve Children With Progressive Low-Grade Glioma: A Canadian Pediatric Brain Tumor Consortium Study. J Clin Oncol 34:3537-3543. doi: 10.1200/JCO.2016.68.1585

18. Henson JW, Ulmer S, Harris GJ (2008) Brain tumor imaging in clinical trials. AJNR Am J Neuroradiol 29:419-424. doi: 10.3174/ajnr.A0963

19. Wang M-Y, Cheng J-L, Han Y-H, et al. (2012) Measurement of tumor size in adult glioblastoma: classical cross-sectional criteria on 2D MRI or volumetric criteria on high resolution 3D MRI? Eur J Radiol 81:2370-2374. doi: 10.1016/j.ejrad.2011.05.017

20. Iliadis G, Selviaridis P, Kalogera-Fountzila A, et al. (2009) The importance of tumor volume in the prognosis of patients with glioblastoma: comparison of computerized volumetry and geometric models. Strahlenther Onkol 185:743-750. doi: $10.1007 / \mathrm{s} 00066-009-2015-7$

21. Schmidt KF, Ziu M, Schmidt NO, et al. (2004) Volume reconstruction techniques improve the correlation between histological and in vivo tumor volume measurements in mouse models of human gliomas. J Neurooncol 68:207-215.

22. Galanis E, Buckner JC, Maurer MJ, et al. (2006) Validation of neuroradiologic response assessment in gliomas: measurement by RECIST, two-dimensional, computer-assisted tumor area, and computer-assisted tumor volume methods. Neuro Oncol 8:156-165. doi: $10.1215 / 15228517-2005-005$

23. Reuter M, Gerstner ER, Rapalino O, et al. (2014) Impact of MRI head placement on glioma response assessment. J Neurooncol 118:123-129. doi: 10.1007/s11060-0141403-8

24. Gilheeney SW, Kieran MW (2012) Differences in molecular genetics between pediatric and adult malignant astrocytomas: age matters. Future Oncol 8:549-558. doi: 
10.2217/fon. 12.51

25. Mistry M, Zhukova N, Merico D, et al. (2015) BRAF mutation and CDKN2A deletion define a clinically distinct subgroup of childhood secondary high-grade glioma. J Clin Oncol 33:1015-1022. doi: 10.1200/JCO.2014.58.3922

26. Olsen ØE (2015) Why measure tumours? Pediatr Radiol 45:35-41. doi: 10.1007/s00247014-3148-0

27. Ellingson BM, Nguyen HN, Lai A, et al. (2016) Contrast-enhancing tumor growth dynamics of preoperative, treatment-naive human glioblastoma. Cancer 122:1718-1727. doi: $10.1002 /$ cncr.29957

28. Akkus Z, Sedlar J, Coufalova L, et al. (2015) Semi-automated segmentation of preoperative low grade gliomas in magnetic resonance imaging. Cancer Imaging 15:12. doi: 10.1186/s40644-015-0047-z

29. Dombi E, Solomon J, Gillespie AJ, et al. (2007) NF1 plexiform neurofibroma growth rate by volumetric MRI: relationship to age and body weight. Neurology 68:643-647. doi: 10.1212/01.wnl.0000250332.89420.e6

30. Porz N, Habegger S, Meier R, et al. (2016) Fully automated enhanced tumor compartmentalization: man vs. machine reloaded. PLoS ONE 11:e0165302. doi: 10.1371/journal.pone.0165302

31. Bø HK, Solheim O, Jakola AS, et al. (2017) Intra-rater variability in low-grade glioma segmentation. J Neurooncol 131:393-402. doi: 10.1007/s11060-016-2312-9 


\section{Figure Legends}

Figure 1: Examples of ROI delineation for volume calculation on FLAIR axial images (A) and linear 2D measurements on the same slice (B). 3D volume rendering of the tumor has been obtained using Osirix compute volume plugin with intergap correction (C) and shows the irregular structure of the tumor which makes inadequate the assessment using linear measurements only.

Figure 2: The tumor in the slice 1 (used for 2D assessment) is stable in baseline and follow-up scans; however on follow up the mass appears to be less bulky in an upper slices (slice 2). The volumetric assessment confirmed the reduction in size (i.e. partial response) that was not appreciable using linear measurement on slice 1 . 


\section{VOLUMETRIC ASSESSMENT OF TUMOR SIZE CHANGES IN PEDIATRIC LOW GRADE GLIOMAS: FEASIBILITY AND COMPARISON WITH LINEAR MEASUREMENTS}

Felice D'Arco ${ }^{1,2^{*}}$ Patricia O'Hare ${ }^{3 *}$, Fatima Dashti ${ }^{1}$, Alvaro Lassaletta ${ }^{4}$, Thalia Loka ${ }^{3}$, Uri Tabori

${ }^{4}$, Giacomo Talenti ${ }^{2}$, Stefanie Thust. ${ }^{5}$, Giancarlo Messalli ${ }^{6}$, Patrick Hales ${ }^{7}$, Eric Bouffet ${ }^{4}$, Suzanne Laughlin ${ }^{1}$

\section{Authors Affiliations:}

${ }^{1}$ Pediatric Neuroradiology, Department of Diagnostic Imaging, The Hospital for Sick Children, Toronto, Canada.

${ }^{2}$ Pediatric Neuroradiology, Department of Radiology, Great Ormond Street Hospital, London, UK

${ }^{3}$ Department of Pediatric Oncology, Great Ormond Street Hospital, London, UK.

${ }^{4}$ Division of Pediatric Neuro-oncology, The Hospital for Sick Children, Toronto, Canada

${ }^{5}$ National Hospital for Neurology and Neurosurgery, Queen Square, London, UK.

${ }^{6}$ Radiology Unit, "Villa Malta" Hospital, Sarno, Italy

${ }^{7}$ Developmental Imaging and Biophysics Section, Institute of Child Health, University College London, London, UK

*FD'A and PO'H are joint first authors and contributed equally to this study.

\section{Corresponding author}

Felice D'Arco

Department of Pediatric Neuroradiology

Great Ormond Street Hospital NHS Trust, WC1N, 3JH

London, United Kingdom

Phone: 0044 (0)20 74059200

Email: Felice.D’Arco@gosh.nhs.uk 

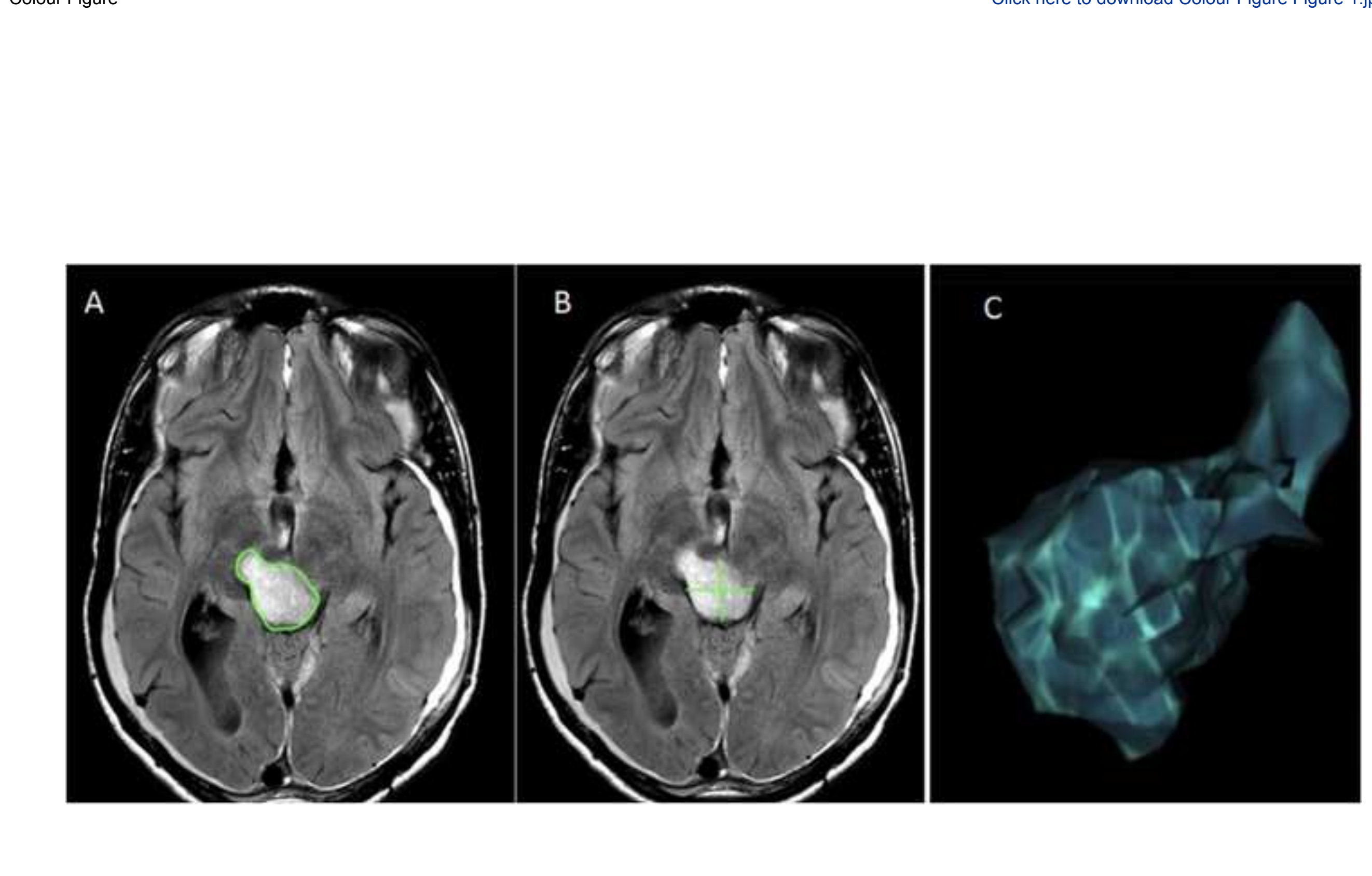

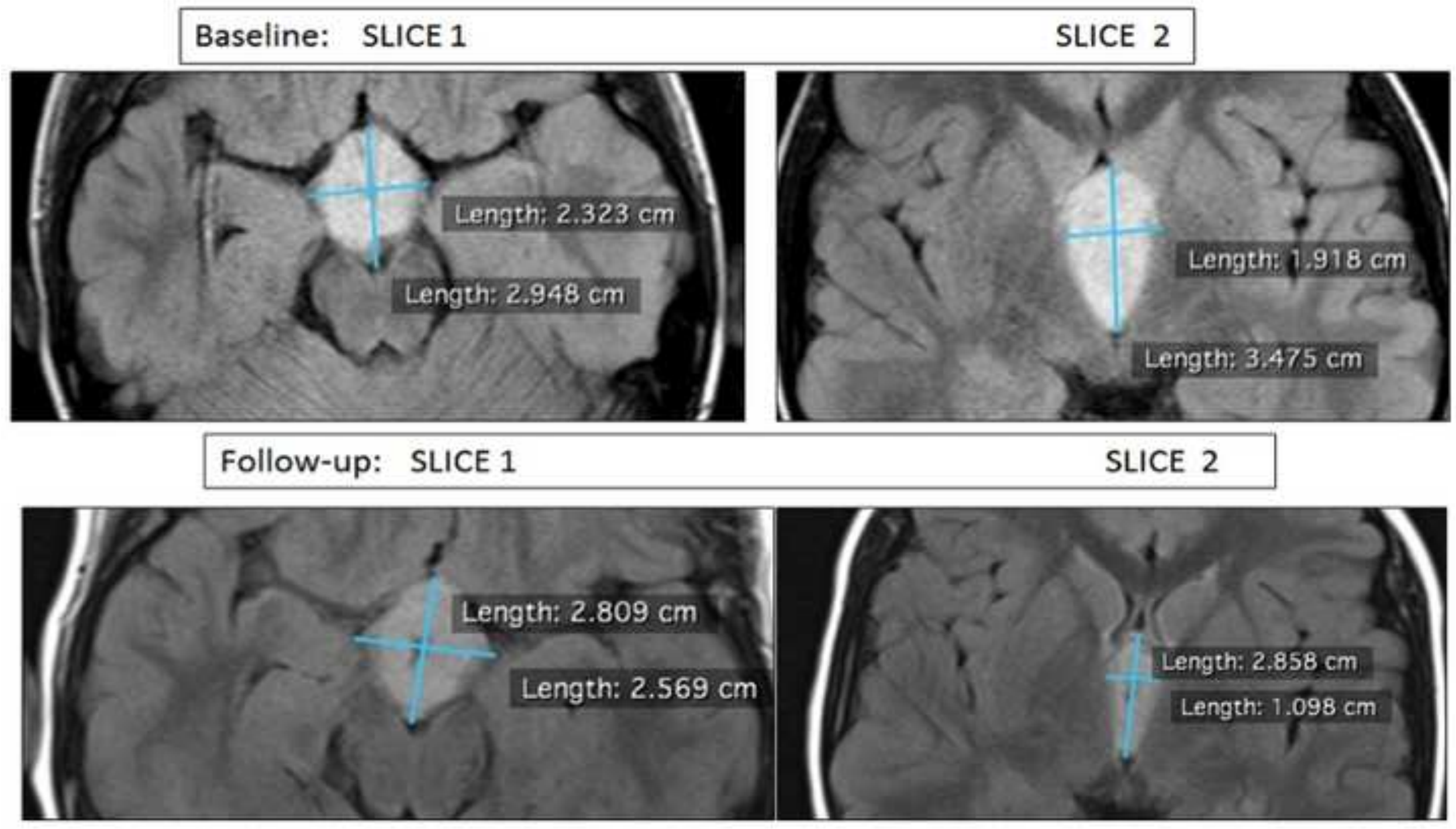
Table 1: Response criteria for both 2D and volumetric assessments (see also Henson et al. AJNR Am J Neuroradiol, 2008 29:419 -24).

\begin{tabular}{|c|c|c|}
\hline $\begin{array}{l}\text { Response } \\
\text { Category }\end{array}$ & 2D & Volumetric \\
\hline $\mathbf{C R}$ & $\begin{array}{l}\text { Complete disappearance of the } \\
\text { lesion on T2 or FLAIR imaging } \\
\text { (if enhancement present, it must } \\
\text { have resolved) }\end{array}$ & Complete disappearance of the lesion \\
\hline PR & $\begin{array}{l}\geq 50 \% \text { decrease in product of } 2 \\
\text { perpendicular diameters }\end{array}$ & $\geq 65 \%$ decrease in volume \\
\hline SD & All others & All others \\
\hline PD & $\begin{array}{l}\geq 25 \% \text { increase in product of } \\
\text { perpendicular diameters }\end{array}$ & $\geq 40 \%$ increase in volume. \\
\hline
\end{tabular}

CR indicates complete response; PR partial response, SD stable disease, PD, progressive disease. Percentage changes are measured from baseline. Product of perpendicular diameter in 2D assessment is measured on the section with the largest tumor area. 
Table 2: Patient Demographics

\begin{tabular}{|c|c|c|c|c|c|}
\hline $\begin{array}{l}\text { Patient } \\
\text { No: }\end{array}$ & Sex & NF1 & $\begin{array}{l}\text { Age } \\
\text { commencing } \\
\text { Vinblastine } \\
\text { (Years) }\end{array}$ & $\begin{array}{l}\text { Location } \\
\text { Tumor }\end{array}$ & Histopathological diagnosis (if known) \\
\hline 1 & $\mathrm{~F}$ & No & 16.75 & Optic Pathway & Pilocytic Astrocytoma \\
\hline 2 & $\mathrm{M}$ & Yes & 16.42 & Optic Pathway & No biopsy \\
\hline 3 & $\mathrm{M}$ & Yes & 9.16 & Optic Pathway & Low Grade Glioma NOS \\
\hline 4 & $\mathrm{M}$ & No & 12.58 & Optic Pathway & Pilocytic Astrocytoma \\
\hline 5 & $\mathrm{~F}$ & Yes & 2.15 & Optic Pathway & No biopsy \\
\hline 6 & $\mathrm{M}$ & No & 7.88 & $\begin{array}{l}\text { Hypothalamic/ } \\
\text { Other }\end{array}$ & Pilocytic Astrocytoma \\
\hline 7 & $\mathrm{~F}$ & Yes & 10.84 & Optic Pathway & No biopsy \\
\hline 8 & $\mathrm{~F}$ & No & 12.16 & Optic Pathway & Pilocytic Astrocytoma \\
\hline 9 & $\mathrm{M}$ & No & 8.72 & Optic Pathway & No biopsy \\
\hline 10 & $\mathrm{M}$ & No & 2.71 & Optic Pathway & \begin{tabular}{|l|} 
Low Grade Glioma NOS \\
\end{tabular} \\
\hline 11 & $\mathrm{M}$ & No & 6.99 & $\begin{array}{l}\text { Hypothalamic/ } \\
\text { Other }\end{array}$ & Pilocytic Astrocytoma \\
\hline 12 & $\mathrm{~F}$ & No & 5.01 & Posterior Fossa & Ganglioglioma \\
\hline 13 & $\mathrm{M}$ & No & 6.80 & Optic Pathway & Ganglioglioma \\
\hline 14 & $\mathrm{M}$ & No & 8.81 & Optic Pathway & Pilocytic Astrocytoma \\
\hline 15 & $\mathrm{~F}$ & No & 8.39 & $\begin{array}{l}\text { Hypothalamic/ } \\
\text { Other }\end{array}$ & Pilocytic Astrocytoma \\
\hline 16 & $\mathrm{~F}$ & No & 6.75 & $\begin{array}{l}\text { Hypothalamic/ } \\
\text { Other, Other }\end{array}$ & Pilomyxoid Astrocytoma \\
\hline 17 & $\mathrm{~F}$ & No & 13.01 & Thalamus & \begin{tabular}{|l|} 
Low Grade Glioma NOS \\
\end{tabular} \\
\hline 18 & $\mathrm{M}$ & No & 16.53 & $\begin{array}{l}\text { Hypothalamic/ } \\
\text { Other }\end{array}$ & Low Grade Glioma NOS \\
\hline 19 & $\mathrm{~F}$ & No & 8.25 & $\begin{array}{l}\text { Hypothalamic/ } \\
\text { Other }\end{array}$ & Low Grade Glioma NOS \\
\hline 20 & $\mathrm{~F}$ & Yes & 5.94 & Optic Pathway & No biopsy \\
\hline 21 & $\mathrm{M}$ & No & 12.08 & Posterior Fossa & Pilocytic Astrocytoma \\
\hline 22 & $\mathrm{~F}$ & Yes & 2.18 & Optic Pathway & No biopsy \\
\hline 23 & $\mathrm{~F}$ & No & 2.27 & Optic Pathway & No biopsy \\
\hline 24 & $\mathrm{M}$ & No & 6.39 & Brainstem & Ganglioglioma \\
\hline 25 & $\mathrm{M}$ & No & 1.53 & Brainstem & Low Grade Glioma NOS \\
\hline 26 & $\mathrm{~F}$ & No & 5.57 & Brainstem & Pilocytic Astrocytoma \\
\hline 27 & $\mathrm{M}$ & No & 1.00 & $\begin{array}{l}\text { Hypothalamic/ } \\
\text { Other }\end{array}$ & Pilomyxoid Astrocytoma \\
\hline 28 & $\mathrm{~F}$ & No & 6.54 & Brainstem & Pilocytic Astrocytoma \\
\hline 29 & $\mathrm{~F}$ & No & 0.57 & Optic Pathway & No biopsy \\
\hline 30 & $\mathrm{M}$ & No & 6.22 & Posterior Fossa & Pilocytic Astrocytoma \\
\hline 31 & $\mathrm{~F}$ & No & 14.48 & Brainstem & Pilocytic Astrocytoma \\
\hline 32 & $\mathrm{~F}$ & No & 4.54 & Posterior Fossa & Pilomyxoid Astrocytoma \\
\hline 33 & $\mathrm{M}$ & No & 11.24 & $\begin{array}{l}\text { Hypothalamic/ } \\
\text { Other }\end{array}$ & Pilocytic Astrocytoma \\
\hline 34 & $\mathrm{M}$ & Yes & 5.85 & Optic Pathway & No biopsy \\
\hline 35 & $\mathrm{~F}$ & No & 0.93 & Optic Pathway & \begin{tabular}{|l|} 
Low Grade Glioma NOS \\
\end{tabular} \\
\hline 36 & $\mathrm{~F}$ & Yes & 3.24 & Optic Pathway & No biopsy \\
\hline 37 & $\mathrm{M}$ & No & 13.38 & Brainstem & Low Grade Glioma NOS \\
\hline 38 & $\mathrm{M}$ & No & 0.56 & Optic Pathway & Low Grade Glioma NOS \\
\hline 39 & $\mathrm{M}$ & No & 11.97 & Optic Pathway & \begin{tabular}{|l|} 
Low Grade Glioma NOS \\
\end{tabular} \\
\hline 40 & $\mathrm{M}$ & No & 6.99 & Optic Pathway & Pilocytic Astrocytoma \\
\hline 41 & $\mathrm{M}$ & No & 5.48 & Brainstem & Ganglioglioma \\
\hline 42 & $\mathrm{M}$ & No & 2.63 & Optic Pathway & Pilocytic Astrocytoma \\
\hline 43 & $\mathrm{~F}$ & No & 13.62 & Optic Pathway & Pilocytic Astrocytoma \\
\hline
\end{tabular}




\begin{tabular}{|l|l|l|l|l|l|}
\hline 44 & M & Yes & 16.42 & Optic Pathway & No biopsy \\
\hline 45 & F & No & 10.26 & Thalamus & Pilocytic Astrocytoma \\
\hline 46 & F & No & 2.09 & Optic Pathway & Low Grade Glioma NOS \\
\hline 47 & M & No & 4.19 & Optic Pathway & Pilocytic Astrocytoma \\
\hline 48 & F & No & 7.59 & Optic Pathway & Pilocytic Astrocytoma \\
\hline 49 & M & No & 15.88 & $\begin{array}{l}\text { Hypothalamic/ } \\
\text { Other }\end{array}$ & Low Grade Glioma NOS \\
\hline 50 & F & No & 12.01 & Optic Pathway & Low Grade Glioma NOS \\
\hline 51 & M & No & 1.42 & Optic Pathway & Pilocytic Astrocytoma \\
\hline 52 & F & No & 11.32 & Optic Pathway & Pilocytic Astrocytoma \\
\hline 53 & M & No & 15.16 & Brainstem & Pilocytic Astrocytoma \\
\hline 54 & M & Yes & 3.28 & Optic Pathway & Pilomyxoid Astrocytoma \\
\hline 55 & M & No & 9.68 & Optic Pathway & No biopsy \\
\hline 56 & F & No & 6.22 & $\begin{array}{l}\text { Hypothalamic/ } \\
\text { Other }\end{array}$ & Pilomyxoid Astrocytoma \\
\hline 57 & F & No & 10.53 & Thalamus & Low Grade Glioma NOS \\
\hline 58 & M & No & 4.06 & Brainstem & Pilocytic Astrocytoma \\
\hline 59 & F & No & 5.66 & Brainstem & Pilocytic Astrocytoma \\
\hline 60 & M & No & 9.82 & Thalamus & Pilocytic Astrocytoma \\
\hline 61 & M & Yes & 2.73 & Optic Pathway & No biopsy \\
\hline 62 & & No & 1.00 & $\begin{array}{l}\text { Hypothalamic/ } \\
\text { Other }\end{array}$ & Pilomyxoid Astrocytoma \\
\hline 63 & M & No & 6.22 & Posterior Fossa & Pilocytic Astrocytoma \\
\hline 64 & & No & 14.48 & Brainstem & Pilocytic Astrocytoma \\
\hline 65 & F & No & 0.93 & Optic Pathway & Low Grade Glioma NOS \\
\hline 66 & M & No & 5.88 & $\begin{array}{l}\text { Hypothalamic/ } \\
\text { Other }\end{array}$ & Low Grade Glioma NOS \\
\hline 67 & F & Yes & 8.01 & Optic Pathway & Ganglioglioma \\
\hline 68 & M & No & 2.24 & Brainstem & Pilocytic Astrocytoma \\
\hline 69 & F & Yes & 10.18 & $\begin{array}{l}\text { Hypothalamic/ } \\
\text { Other }\end{array}$ & No biopsy \\
\hline 70 & F & No & 3.87 & Optic Pathway & No biopsy \\
\hline
\end{tabular}


Table 3: Results of the tumor response assessment.

\begin{tabular}{|c|c|c|c|c|c|c|}
\hline $\begin{array}{l}\text { Pt } \\
\text { No: }\end{array}$ & $\begin{array}{l}\text { \% change via } \\
\text { volumetric } \\
\text { assessment }\end{array}$ & \begin{tabular}{|lr}
$\%$ & change \\
via & $2 \mathrm{D}$ \\
assessment
\end{tabular} & $\begin{array}{l}\text { Volumetric } \\
\text { Tumor } \\
\text { response }\end{array}$ & $\begin{array}{l}\text { 2D } \\
\text { tumor } \\
\text { response }\end{array}$ & $\begin{array}{l}\text { Location of } \\
\text { Tumor }\end{array}$ & $\begin{array}{l}\text { Histopathological } \\
\text { diagnosis (if known) }\end{array}$ \\
\hline 1 & $-56.37 \%$ & $-52.08 \%$ & $\mathrm{SD}(\mathrm{MR})$ & PR & Optic Pathway & Pilocytic Astrocytoma \\
\hline 2 & $-12.33 \%$ & $-12.59 \%$ & SD & SD & Optic Pathway & \\
\hline 3 & $18.76 \%$ & $3.41 \%$ & SD & SD & Optic Pathway & $\begin{array}{lll}\text { Low } & \text { Grade } & \text { Glioma } \\
\text { NOS } & & \\
\end{array}$ \\
\hline 4 & $-9 \%$ & $-17.43 \%$ & SD & SD & Optic Pathway & Pilocytic Astrocytoma \\
\hline 5 & $-47.66 \%$ & $-20 \%$ & $\mathrm{SD}(\mathrm{MR})$ & SD & Optic Pathway & \\
\hline 6 & $-65.30 \%$ & $-33.31 \%$ & PR & $\mathrm{SD}(\mathrm{MR})$ & Midline, Other & Pilocytic Astrocytoma \\
\hline 7 & $-23.50 \%$ & $-9.00 \%$ & SD & SD & Optic Pathway & \\
\hline 8 & $-20 \%$ & $-23.40 \%$ & SD & SD & Optic Pathway & Pilocytic Astrocytoma \\
\hline 9 & $47.50 \%$ & $5.30 \%$ & PD & SD & Optic Pathway & \\
\hline 10 & $7.13 \%$ & $14.32 \%$ & SD & SD & Optic Pathway & $\begin{array}{l}\text { Low } \\
\text { NOS }\end{array}$ \\
\hline 11 & $-48.84 \%$ & $-27.67 \%$ & $\mathrm{SD}(\mathrm{MR})$ & SD (MR) & Midline, Other & Pilocytic Astrocytoma \\
\hline 12 & $27.62 \%$ & $38.33 \%$ & SD & PD & $\begin{array}{l}\text { Posterior } \\
\text { Fossa }\end{array}$ & Ganglioglioma \\
\hline 13 & $52 \%$ & $-3.60 \%$ & PD & SD & Optic Pathway & Ganglioglioma \\
\hline 14 & $-38.48 \%$ & $-26.76 \%$ & $\mathrm{SD}(\mathrm{MR})$ & SD (MR) & Optic Pathway & Pilocytic Astrocytoma \\
\hline 15 & $28.56 \%$ & $0.90 \%$ & SD & SD & Midline, Other & Pilocytic Astrocytoma \\
\hline 16 & $-30.63 \%$ & $-10.90 \%$ & SD & SD & Midline, Other & $\begin{array}{l}\text { Pilomyxoid } \\
\text { Astrocytoma }\end{array}$ \\
\hline 17 & $21.87 \%$ & $22.89 \%$ & SD & SD & Thalamus & $\begin{array}{lll}\text { Low } & \text { Grade } & \text { Glioma } \\
\text { NOS } & & \\
\end{array}$ \\
\hline 18 & $-26.13 \%$ & $-20.16 \%$ & SD & SD & Midline, Other & $\begin{array}{lll}\text { Low } & \text { Grade } & \text { Glioma } \\
\text { NOS } & & \\
\end{array}$ \\
\hline 19 & $34.87 \%$ & $33.06 \%$ & SD & PD & Midline, Other & $\begin{array}{l}\text { Low } \text { Grade } \text { Glioma } \\
\text { NOS }\end{array}$ \\
\hline 20 & $-55.30 \%$ & $-61.25 \%$ & SD (MR) & PR & Optic Pathway & \\
\hline 21 & $14.78 \%$ & $18.81 \%$ & SD & SD & $\begin{array}{l}\text { Posterior } \\
\text { Fossa }\end{array}$ & Pilocytic Astrocytoma \\
\hline 22 & $-40 \%$ & $-43.53 \%$ & SD (MR) & SD (MR) & Optic Pathway & \\
\hline 23 & $153 \%$ & $97.30 \%$ & $\mathrm{PD}$ & PD & Optic Pathway & \\
\hline 24 & $30.50 \%$ & $18.40 \%$ & SD & SD & Brainstem & Ganglioglioma \\
\hline 25 & $3.70 \%$ & $-4 \%$ & SD & SD & Brainstem & $\begin{array}{lll}\text { Low } & \text { Grade } & \text { Glioma } \\
\text { NOS } & & \\
\end{array}$ \\
\hline 26 & $78 \%$ & $108.27 \%$ & PD & PD & Brainstem & Pilocytic Astrocytoma \\
\hline 27 & $-41.31 \%$ & $-35.43 \%$ & $\mathrm{SD}(\mathrm{MR})$ & $\mathrm{SD}(\mathrm{MR})$ & Midline, Other & $\begin{array}{l}\text { Pilomyxoid } \\
\text { Astrocytoma }\end{array}$ \\
\hline 28 & $-12.50 \%$ & $2.10 \%$ & SD & SD & Brainstem & Pilocytic Astrocytoma \\
\hline 29 & $-19 \%$ & $-55 \%$ & SD & PR & Optic Pathway & \\
\hline 30 & $-38.86 \%$ & $-16.65 \%$ & $\mathrm{SD}(\mathrm{MR})$ & SD & $\begin{array}{l}\text { Posterior } \\
\text { Fossa }\end{array}$ & Pilocytic Astrocytoma \\
\hline 31 & $-49.40 \%$ & $-41.40 \%$ & SD (MR) & $\mathrm{SD}(\mathrm{MR})$ & Brainstem & Pilocytic Astrocytoma \\
\hline 32 & $15.14 \%$ & $13.12 \%$ & SD & SD & $\begin{array}{l}\text { Posterior } \\
\text { Fossa }\end{array}$ & $\begin{array}{l}\text { Pilomyxoid } \\
\text { Astrocytoma }\end{array}$ \\
\hline 33 & $113 \%$ & $61.53 \%$ & $\mathrm{PD}$ & PD & Midline, Other & Pilocytic Astrocytoma \\
\hline 34 & $-24 \%$ & $-13.00 \%$ & SD & SD & Optic Pathway & \\
\hline 35 & $202.08 \%$ & $100.86 \%$ & PD & PD & Optic Pathway & $\begin{array}{lll}\text { Low } & \text { Grade } & \text { Glioma } \\
\text { NOS } & & \\
\end{array}$ \\
\hline 36 & $-43.12 \%$ & $-9.01 \%$ & SD (MR) & SD & Optic Pathway & \\
\hline 37 & $9.84 \%$ & $9.03 \%$ & SD & SD & Brainstem & $\begin{array}{lll}\text { Low } & \text { Grade } & \text { Glioma } \\
\text { NOS } & & \\
\end{array}$ \\
\hline
\end{tabular}




\begin{tabular}{|c|c|c|c|c|c|c|}
\hline 38 & $72.69 \%$ & $39.85 \%$ & PD & PD & Optic Pathway & $\begin{array}{lll}\text { Low } & \text { Grade } & \text { Glioma } \\
\text { NOS } & & \\
\end{array}$ \\
\hline 39 & $-83.19 \%$ & $-77.52 \%$ & PR & PR & Optic Pathway & $\begin{array}{lll}\text { Low } & \text { Grade } & \text { Glioma } \\
\text { NOS } & \end{array}$ \\
\hline 40 & $15.93 \%$ & $6.90 \%$ & SD & SD & Optic Pathway & Pilocytic Astrocytoma \\
\hline 41 & $3.80 \%$ & $-7.80 \%$ & SD & SD & Brainstem & Ganglioglioma \\
\hline 42 & $-3.40 \%$ & $-30.10 \%$ & SD & SD (MR) & Optic Pathway & Pilocytic Astrocytoma \\
\hline 43 & $-67.31 \%$ & $-52.31 \%$ & PR & PR & Optic Pathway & Pilocytic Astrocytoma \\
\hline 44 & $-12.33 \%$ & $-12.59 \%$ & SD & SD & Optic Pathway & \\
\hline 45 & $116.49 \%$ & $76 \%$ & PD & $\mathrm{PD}$ & Thalamus & Pilocytic Astrocytoma \\
\hline 46 & $-27.65 \%$ & $-46.85 \%$ & SD & SD (MR) & Optic Pathway & $\begin{array}{lll}\text { Low } & \text { Grade } & \text { Glioma } \\
\text { NOS } & & \\
\end{array}$ \\
\hline 47 & $125.81 \%$ & $99.06 \%$ & PD & PD & Optic Pathway & Pilocytic Astrocytoma \\
\hline 48 & $4.60 \%$ & $-1.54 \%$ & SD & SD & Optic Pathway & Pilocytic Astrocytoma \\
\hline 49 & $-84.68 \%$ & $-55.42 \%$ & PR & PR & Midline, Other & $\begin{array}{lll}\text { Low } & \text { Grade } & \text { Glioma } \\
\text { NOS } & & \\
\end{array}$ \\
\hline 50 & $-7 \%$ & $-3.50 \%$ & SD & SD & Optic Pathway & $\begin{array}{lll}\text { Low } & \text { Grade } & \text { Glioma } \\
\text { NOS } & & \\
\end{array}$ \\
\hline 51 & $-67.30 \%$ & $-53.42 \%$ & PR & PR & Optic Pathway & Pilocytic Astrocytoma \\
\hline 52 & $11.63 \%$ & $41.37 \%$ & SD & PD & Optic Pathway & Pilocytic Astrocytoma \\
\hline 53 & $-27.52 \%$ & $-19.72 \%$ & $\mathrm{SD}$ & SD & Brainstem & Pilocytic Astrocytoma \\
\hline 54 & $3.54 \%$ & $-7.10 \%$ & SD & SD & Optic Pathway & $\begin{array}{l}\text { Pilomyxoid } \\
\text { Astrocytoma }\end{array}$ \\
\hline 55 & $-43.20 \%$ & $-65.87 \%$ & SD (MR) & PR & Optic Pathway & \\
\hline 56 & $131.62 \%$ & $64 \%$ & PD & PD & Midline, Other & $\begin{array}{l}\text { Pilomyxoid } \\
\text { Astrocytoma }\end{array}$ \\
\hline 57 & $-65.87 \%$ & $-50.40 \%$ & PR & PR & Thalamus & $\begin{array}{lll}\text { Low } & \text { Grade } & \text { Glioma } \\
\text { NOS } & & \\
\end{array}$ \\
\hline 58 & $12.36 \%$ & $-55.55 \%$ & SD & PR & Brainstem & Pilocytic Astrocytoma \\
\hline 59 & $48.43 \%$ & $62.81 \%$ & PD & $\mathrm{PD}$ & Brainstem & Pilocytic Astrocytoma \\
\hline 60 & $4.20 \%$ & $78.90 \%$ & SD & PD & Thalamus & Pilocytic Astrocytoma \\
\hline 61 & $12.63 \%$ & $37.20 \%$ & SD & PD & Optic Pathway & \\
\hline 62 & $10.98 \%$ & 7.92 & SD & SD & Midline, Other & $\begin{array}{l}\text { Pilomyxoid } \\
\text { Astrocytoma }\end{array}$ \\
\hline 63 & $-18.34 \%$ & $-30.48 \%$ & SD & SD (MR) & $\begin{array}{l}\text { Posterior } \\
\text { Fossa }\end{array}$ & Pilocytic Astrocytoma \\
\hline 64 & $-47.55 \%$ & $-35.20 \%$ & $\mathrm{SD}(\mathrm{MR})$ & $\mathrm{SD}(\mathrm{MR})$ & Brainstem & Pilocytic Astrocytoma \\
\hline 65 & $202.08 \%$ & $100.86 \%$ & PD & PD & Optic Pathway & $\begin{array}{lll}\text { Low } & \text { Grade } & \text { Glioma } \\
\text { NOS } & & \\
\end{array}$ \\
\hline 66 & $29.62 \%$ & $30.75 \%$ & SD & PD & Midline, Other & $\begin{array}{lll}\text { Low } & \text { Grade } & \text { Glioma } \\
\text { NOS } & & \\
\end{array}$ \\
\hline 67 & $-17.65 \%$ & $-40.41 \%$ & SD & $\mathrm{SD}(\mathrm{MR})$ & Optic Pathway & Ganglioglioma \\
\hline 68 & $49.34 \%$ & $45.34 \%$ & PD & $\mathrm{PD}$ & Brainstem & Pilocytic Astrocytoma \\
\hline 69 & $58.78 \%$ & $39.80 \%$ & $\mathrm{PD}$ & $\mathrm{PD}$ & Midline, Other & \\
\hline 70 & $-26.19 \%$ & $-20.09 \%$ & SD & SD & Optic Pathway & \\
\hline
\end{tabular}

Patients who had discordant results of the tumor response assessment are highlighted. SD: stable disease; PD: progressive disease; PR: partial response; MR: minor response. 
Electronic Supplementary Material

\section{Click here to access/download \\ Electronic Supplementary Material Supplemental Table .docx}



Click here to view linked References $\underline{\underline{\boldsymbol{}}}$

Blinded Manuscript ( Marked/ no author name/ Institution) Click here to view linked References $\underline{\underline{\boldsymbol{}}}$ )

)

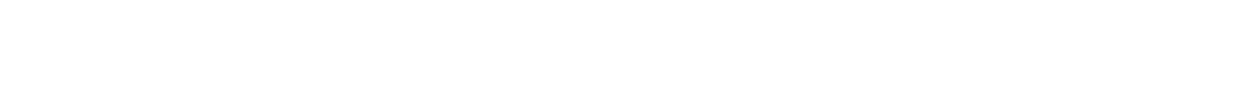
(a) (1) $\sqrt{1}$

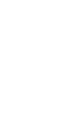
(1)

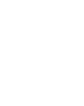

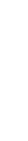

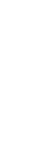

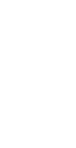

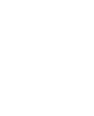
( .

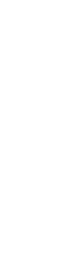

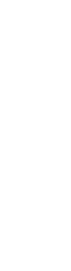

